Military Technical College Kobry El-Kobbah, Cairo, Egypt

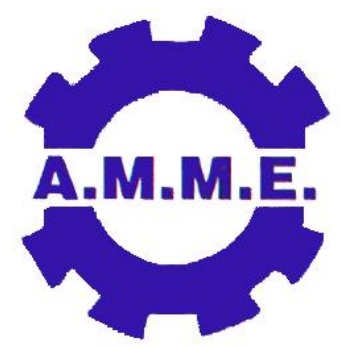

$14^{\text {th }}$ International Conference on Applied Mechanics and Mechanical Engineering.

\title{
Simulation and analysis of hot forging process for industrial locking gear elevators
}

By

M. Maarefdoust*

M. Kadkhodayan**

\begin{abstract}
:
In this paper hot forging process for industrial locking gear elevators is simulated and analyzed. An increase in demand of industrial locking gear elevators with better quality and lower price caused the machining process to be replaced by hot forging process. Production of industrial locking gear elevators by means of hot forging process is affected by many parameters such as billet temperature, geometry of die and geometry of pre-formatted billet. In this study the influences of billet temperature on effective plastic strain, radius of die corners on internal stress of billet and thickness of flash on required force of press are investigated by means of computer simulation. Three-dimensional modeling of initial material and die are performed by Solid Edge, while simulation and analysis of forging are performed by Super Forge. Based on the computer simulation the required dies are designed and the work pieces are formed. Comparison of simulation results with experimental data demonstrates great compatibility.
\end{abstract}

\section{Keywords:}

locking gear, Finite volume method, Computer simulation, Forging. 
* Islamic Azad University-Gonabad Branch, Iran, (m_maarefdoost@yahoo.com).

** Associate Professor, Mechanical engineering department, Ferdowsi University of Mashhad, Iran.

\section{Introduction:}

Forging process is one of the popular methods in metal forming. Many of the industrial parts are produced by this method because of its high strength and production rate of parts. Parameters such as temperature, geometry of raw material and die are effective in reducing production cost and increasing part quality. If the design and manufacturing of parts are on basis of experience that results in time waste and high cost. The prediction of material flow can be achieved completely by computer simulation. Main parameters in computer simulation are filling the die completely without leaving any defect, reducing material loss and stress in die and increasing die life. In order to reduce the cost of forging process and make it competent with other production methods, it is essential to optimize the design of part and die. Moreover, considering required forces, energy and time in such a way to attain an accurate analysis and design could be highly important. Therefore, using of the accurate computer simulation can be an effective method for reaching these goals. Forging of complex parts is usually performed in several steps. Design of step numbers, step types and intermediate steps (pre-forms) along with the design of final die, forging parameters and process conditions are the most complex tasks in forging simulation. Generally, application of computer to design the required steps based on analytical and experimental data has been considered excessively by other researches previously. However, Finite Volume Methods (FVM) are accepted especially today as a powerful method to be used widely to analyze various bulk metal forming processes including forging. As a result of extensive research on FVM different commercial softwares have been obtained with the capability of simulating different metal forming processes. By applying them one can build a virtual model of dies and defines different materials characteristics in order to simulate the forging process precisely and to get valuable information from the way that material is being formed in die. Thus it can be guaranteed that the parts have desired shapes before making the die. In addition, using the results of performed numerical analysis many of the important design parameters such as forming forces, stresses on the part and die and also plastic energy are determined. Because of the functions and capabilities of this method in simulating the process, the manufactures know this method as the so-called virtual production. In the past decade, most of computer aided research studies about the forging process were based on finite element method. However, the forged parts have large deformation and distortion and the simulation based on finite element method will be a time consuming process with not too accurate results. Thus, today this method is being replaced with the finite volume method (FVM) [1]. Several researches have been done on design of forging dies. Behrens and colleagues have applied Super Forge (FVM software) to design the vehicle's propeller shaft [2]. To analyze the bending deformations of thick and thin plates, $\mathrm{M}$. Wheel and his colleagues have used FVM [3]. V. Rranatunga et al have applied FVM method to design furrow of dies in closed die forging [4]. Eivazi made a software package called Auto Forge in order to automate the hot forging process of round parts [5]. Sanaie and Jafari, compared closed die forging for two parts based on three methods: analytical method (Qachy method), numerical method (ANSYS), and experimental method. Some analytical and numerical methods predict more or 
less load compared to experimental method, respectively [6]. In this paper, the modeling and analysis of hot forging process for a locking gear has been investigated by Super Forge and the deformation mechanism is investigated in detail.

\section{Materials and Method:}

First step in design of die for the locking gear is to define a three dimensional model of the work piece in the Solid Edge, which is a modeling software. Then, the initial model will be transformed to the final shape of the work piece. Materials of work piece and die are steel CK45 (DIN 1.1191) and steel H13 (DIN 1.2344), respectively. Forging process for producing locking gear is performed in two stages. In the first stage (pre-form) the work piece will achieve its suitable diameter by reducing its height. In the second stage the work piece will obtain its final shape after trimming. Fig. 1 illustrates the position of the work piece within the die. Input data to the software is extracted from reference [7]. Tables 1, 2 show the software's input data, including type of press, materials of piecework and die. In the next part, numerical simulation of the metal forming process will be explained.

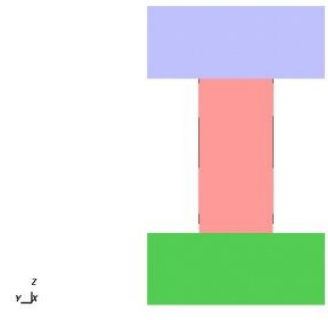

(a)

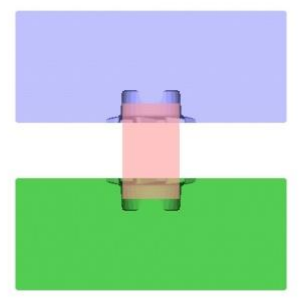

(b)

Figure(1):Locations the parts inside the die, (a) template die to reduce the height, (b) the final die

Table (1): The used input data

\begin{tabular}{|c|c||c|c|c|}
\hline $\begin{array}{c}\text { Billet } \\
\text { Material }\end{array}$ & Din1.1191 \\
\hline Die Material & Din .2344 \\
\hline $\begin{array}{c}\text { Die } \\
\text { temperature }\end{array}$ & $200^{\circ} \mathrm{C}$ & $\begin{array}{c}\text { Crank } \\
\text { radius(R) }\end{array}$ & $150(\mathrm{~mm})$ \\
\hline Press kind & $\begin{array}{c}\text { Crankshaft } \\
\text { press }\end{array}$ \\
\hline $\begin{array}{c}\text { Ambient } \\
\text { Temperature }\end{array}$ & $25^{\circ} \mathrm{R}$ & Rod length(L) & $690(\mathrm{~mm})$ \\
\hline
\end{tabular}

\section{1- Forming simulation without pre-form:}

Considering the size of workpiece and minimization of waste material, the height and diameter of the initial billet are chosen to be $75 \mathrm{~mm}$ and $45 \mathrm{~mm}$, respectively. Without any pre- 
form, the final shape of workpiece has been achieved in one stage of forming. Figure 2 shows the position of the workpiece within the die, while Fig. 3 illustrates the forging stages. The simulation results indicate that metal flows as intended and completely fill the die cavities, thus the final product will not have any defect. However, based on some experiences, it is quite difficult to place the initial billet accurately inside the die and consequently the metal will not flow properly. On the other hand, small width of flash will make the trimming process a hard task. Thus this method is not suitable for production.

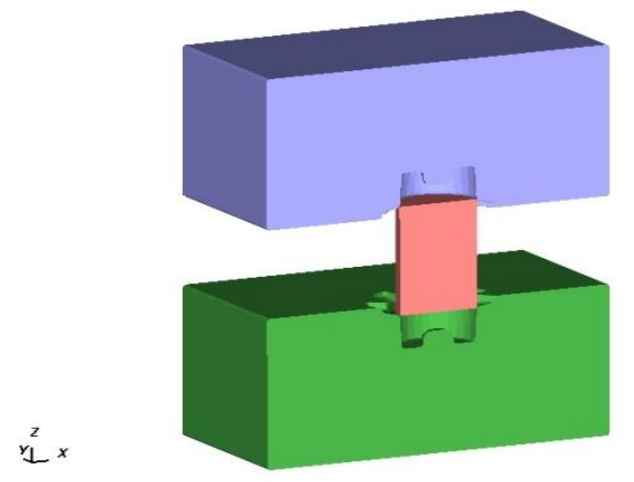

Figure (2): Workpiece in the die without pre-form

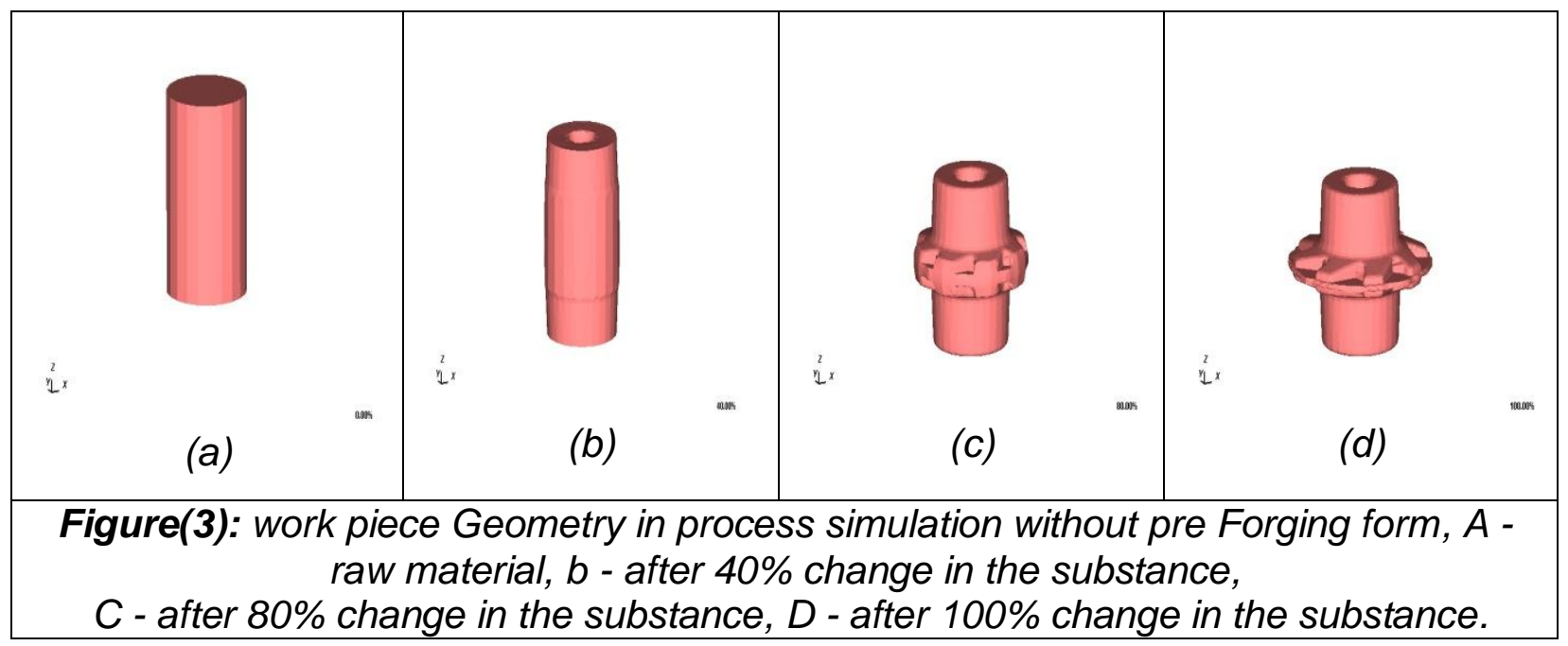

\section{2-Forming simulation with pre-form:}

Based on some experimental evidences, a two stages forging process was designed. The first stage is a pre-form including height reduction. In the second stage the billet will be placed in the final die and to find its final shape. Finally, after some trimming the workpiece will be ready for machining.

\section{A - Simulation of height reduction stage:}

Addition of a pre-form stage to forging process will ease the placement of billet in the final die. In the pre-form stage the work piece will achieve the suitable diameter based on the diameter of final die. Advantages of using height reduction pre-form can be expressed as [8]: 1-obtaining the desired diameter, 2- scale removal of initial billet, and 3-proper material flow in the final die. Height and diameter of initial billet is chosen to be $90 \mathrm{~mm}$ and $40 \mathrm{~mm}$ 
respectively. After pre-form stage height and diameter will be reduced to $85 \mathrm{~mm}, 42 \mathrm{~mm}$ respectively. As it is mentioned earlier, scale removal is one of the pre-form benefits. Scale removal will take away the oxide layer from the surface of initial materials which will improve the surface quality of work piece. In fact, the height reduction stage will cause the billet fiber to approach toward the final fiber structure of work piece which facilitating the flow of materials in the final die. Figure (4) shows the fiber structure in the height reduction stage. In the simulation stage, the initial billet will be the input of height reduction stage and its output, in turn, will be the input of the second stage (final forming). Figure (1) illustrates the position of initial billet in the height reduction stage.

\section{B - Simulation of final forming stage:}

In this stage, the obtained workpiece from the height reduction stage will be placed in the final die, Fig. 5. Because the diameter of pre-formed workpiece is fit for the final die, it can be easily placed inside it. Figure 6 depicts the forging process stages for a locking gear. After initial height reduction process, the work piece will be placed in the final die for final forming process. Then and based on the suitable width of the flash, the trimming process can be performed easily.

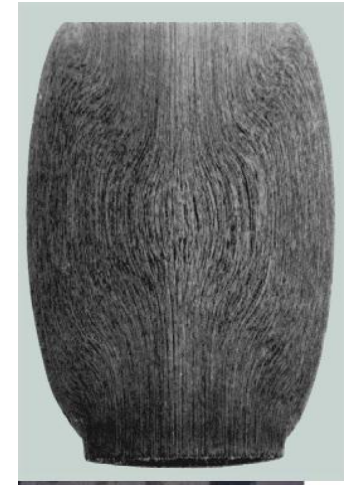

Figure (4): Deformed fibers in step height

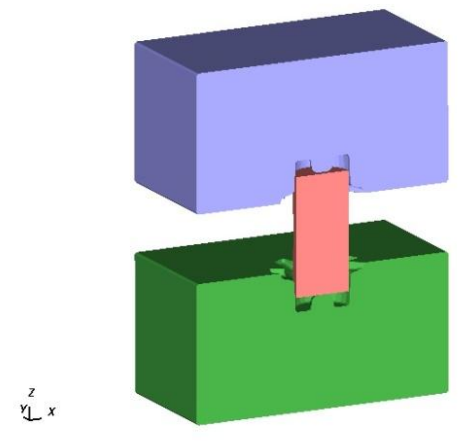

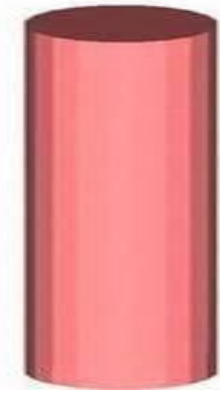

(a)

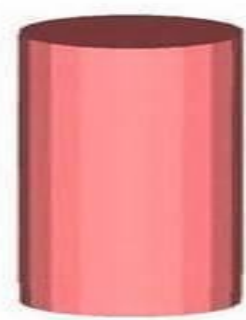

(b)

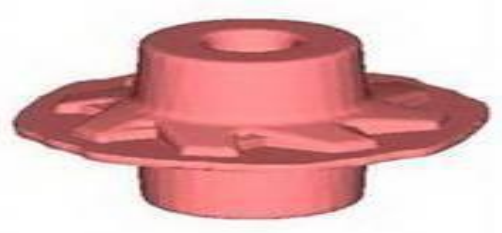

(c)

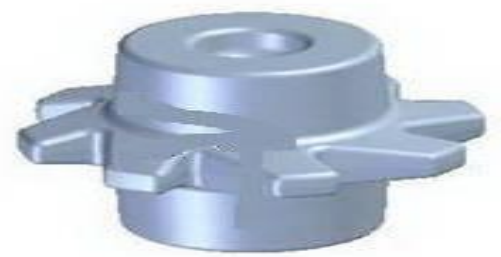

(d)

Figure (6). Simulation of part production, (a) raw material, (b) reduction of height,

(c) final formation, (d) flashing

\section{Results and Discussion:}

Figure (5): Position of one piece pre-form

In this part the basic variables which affect the forging process such as flash thickness, temperature and die corner radius are investigated. Then, based on the most appropriate values of temperature, die radius and flash thickness was chosen for the purpose of die production.

\section{1 -Effect of temperature}


The purpose of this part is to monitor the effect of temperature on the effective plastic strain during the final forming stage. In this test, a pre-formed workpieces with temperatures of 900 , 950,1000 and $1050^{\circ} \mathrm{C}$ are placed inside the final die [9] and the maximum effective plastic strains at various temperatures are obtained, Fig. 7. The distribution of effective plastic strain at different temperatures is illustrated in Fig. 8 . When the temperature goes beyond a specific value, the surface quality of the workpiece decreases seriously because of the formation of oxide layers [9]. In this study, the temperature value of $1050^{\circ} \mathrm{C}$, which was obtained based on my own experience, was selected for forging of locking gear.

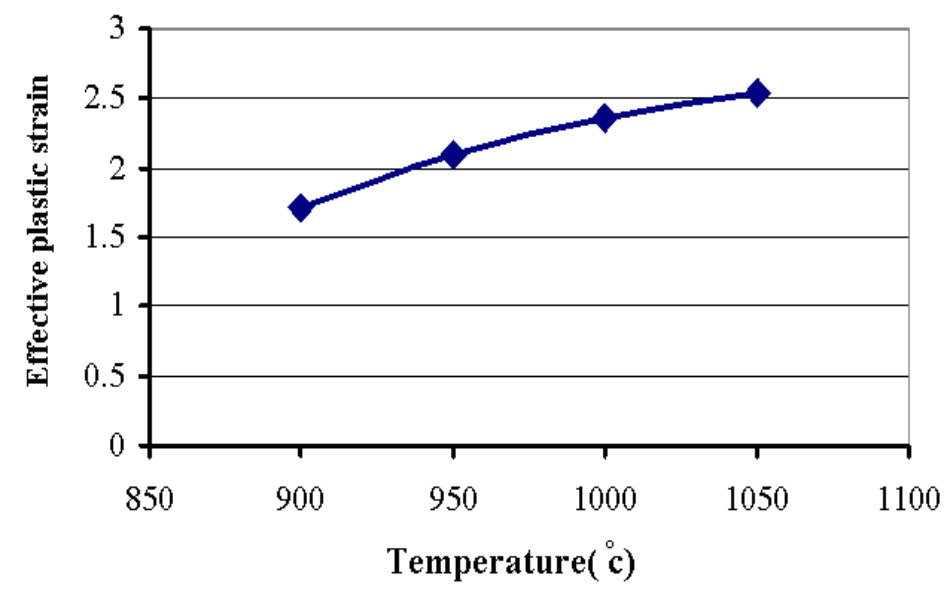

Figure(7): Effect of temperature on the maximum effective plastic strain

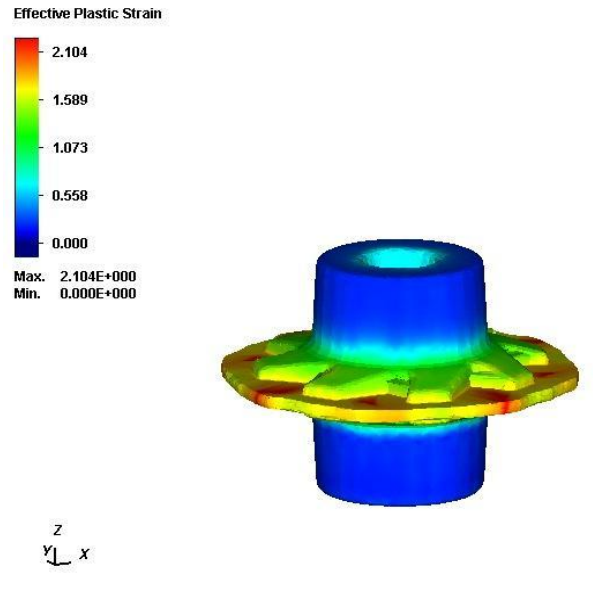

effective plastic strain in $950^{\circ} \mathrm{C}$

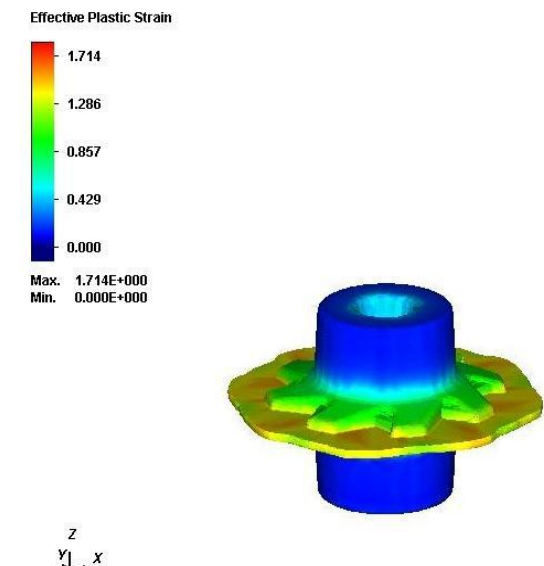

$100.00 \%$ 

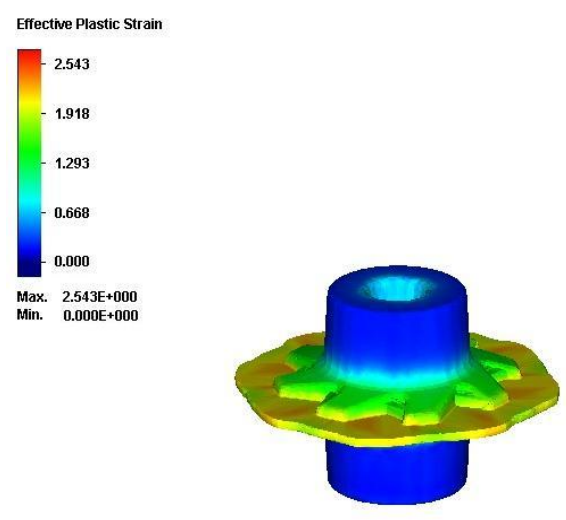

$x^{2}-x$

effective plastic strain in $1050^{\circ} \mathrm{C}$
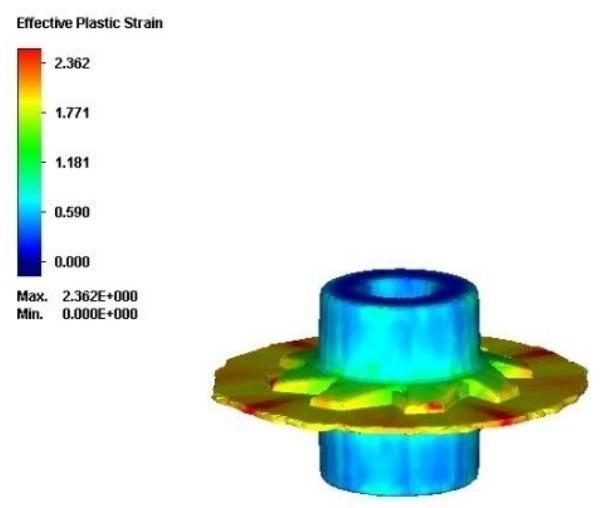

Y $^{2}+x$

$100.00 \%$ Figure(8): Effect of temperature on effective plastic strain

\section{2- Effect of die corner radius}

The effect of die corner radius on the effective stress in the work piece is investigated here. For the selected radiuses $(2,2.5$ and $3 \mathrm{~mm})$, the maximum effective stresses are obtained, Fig. 9. Now, 3D models of dies with different radiuses were designed in Solid Edge. Then the obtained results are transferred to the FVM software. The minimum and maximum amounts of effective stresses are achieved at die corner radiuses of 3 and $2 \mathrm{~mm}$, respectively. The main reason for this observation is the easier flow of metal inside the die. Therefore, in this study radius of $3 \mathrm{~mm}$ was selected for the design of final die. Von mises stress distribution at different radiuses of die is shown in Fig. 10.

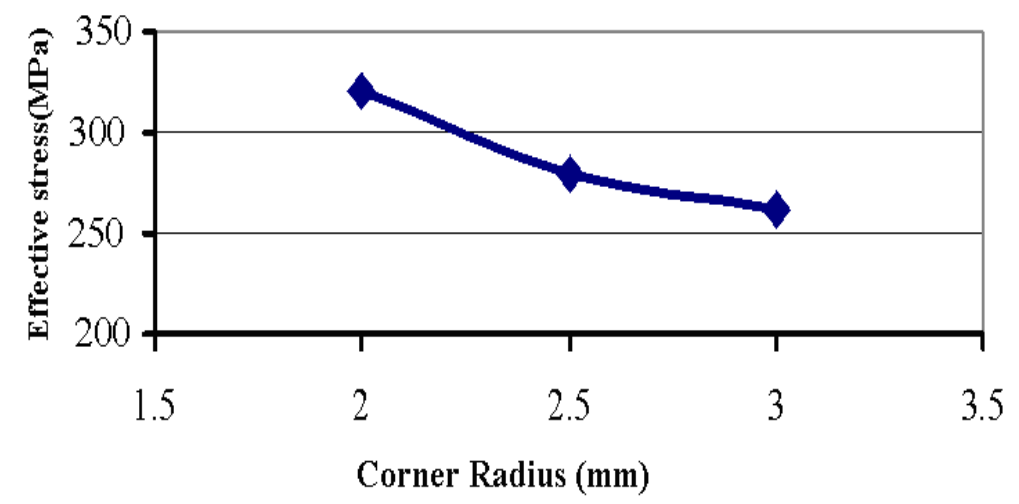

Figure(9): Variation of the effective stress with die corners radius 

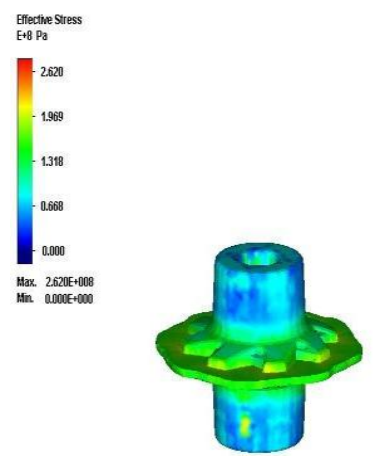

$\operatorname{lin}^{2} x$

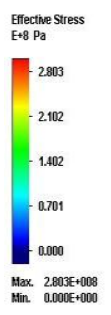

$x_{1}^{2} x$

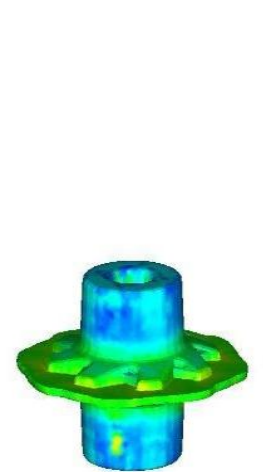

$100.00 \%$

Effective stress $r=3(\mathrm{~mm}) \quad$ Effective stress $r=2.5(\mathrm{~mm})$ Figure(10): The effect of die corner radius on the workpiece stress

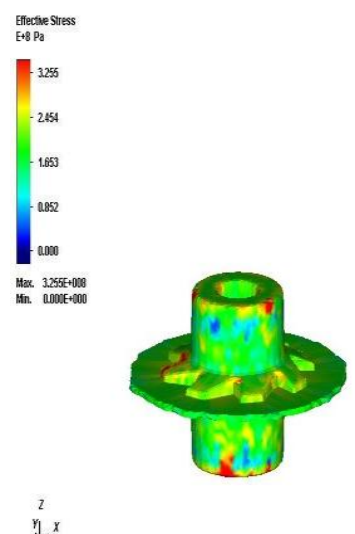

Effective stress $r=2(\mathrm{~mm})$

\section{3 - Thickness of flash}

The purpose of this test is to evaluate the effect of flash thickness on the press force. For the selected flash thicknesses $(1.8,2,2.5$ and $3 \mathrm{~mm})$, the required press forces are obtained, Fig. 11. It has to be pointed out that the flash thickness is directly related to the amount of waste material. Thus, an optimal flash thickness should be chosen based on the capacity of press, life time of die and the number of products. According to Fig. 12, the press force increases significantly during the formation of flash. Hence, the smaller flash thickness will exert more pressure to the die and may cause break. On the other hand, the bigger flash thickness will cause more waste material which in turn increases the production cost. Hence, the designer has to find the most appropriate thickness of flash by considering the factors such as workpiece and die materials and the required number of work pieces [10]. The obtained results show that the maximum and minimum press loads belong to the flash thickness of $1.8 \mathrm{~mm}$ and $3 \mathrm{~mm}$, respectively. In this study, considering the number of produced workpieces, their materials, die and press capacity, the flash thickness was taken as $3 \mathrm{~mm}$.

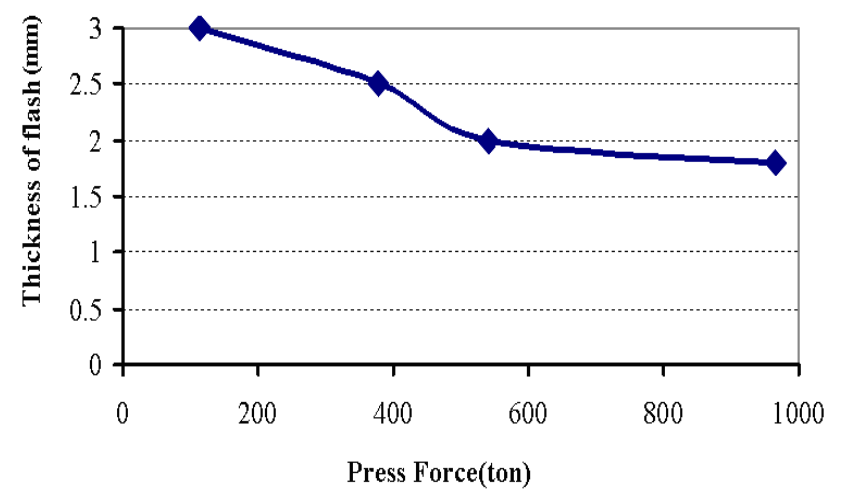

Figure (11): Variation of flash thickness with press force

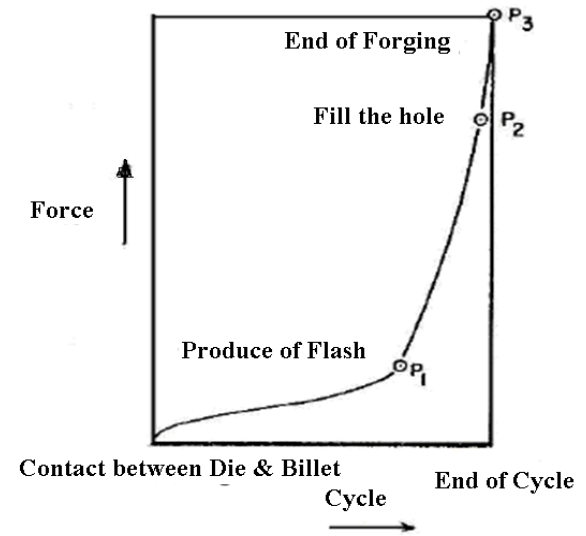

Figure (12): The Curve of Force-Cycle in Forging

After various experiments have been carried out and different parameters were investigated, the following results have been achieved:

- The effective plastic strain will increase with rising of temperature (Fig. 7). But it must be 
noted that if the temperature amount exceeds a certain limit, the workpiece will fail, and the final product will be defective [9].

- The effective stress decreases as radius of corners increases, (Fig. 9).

- With an increase in the flash thickness, the required press force will decrease, (Fig. 11). This point should also be taken into account that the flash thickness is directly related to the amount of waste material. Thus the most favorable flash thickness should be chosen based on the capacity of press, life time of die and number of products, [1].

- By changing the locking gear production process from machining to forging, the costs and time of production will reduce significantly.

- the obtained results from production process indicates that we cannot ignore the role of experience and practical conditions on forging process of locking gear and only rely on the computer simulation. It must be noted that the computer simulation cannot create all of the practical condition.

Finally, the proper amounts of parameters have been chosen based on the obtained results, and comparison of practical data with numerical simulation shows great consistency, (Fig. 13).

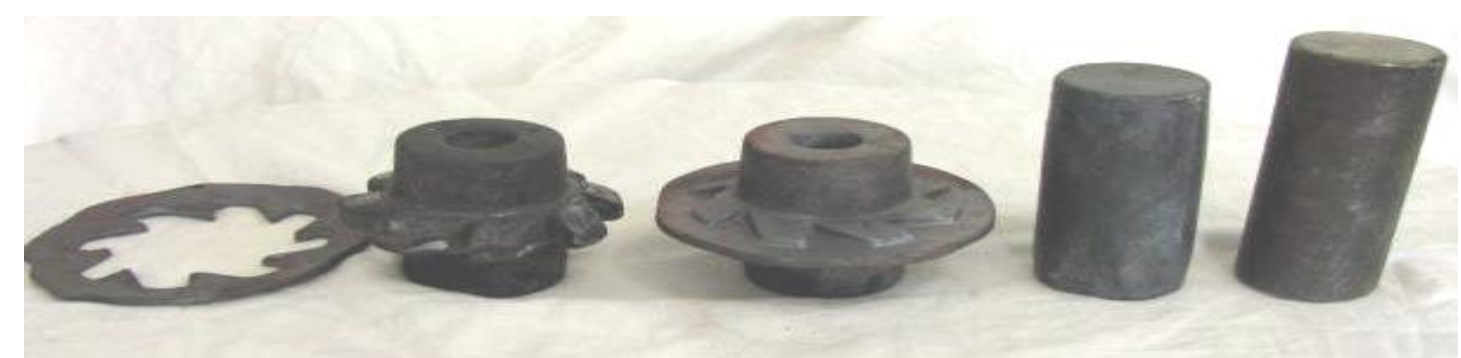

\section{Conclusion:}

Figure (13): Parts produced in different stages

Hot forging process for industrial locking gear elevator has been simulated and analyzed by Super Forge software. The simulation of forging process was performed in two stages, in the first stage the height reduction process was applied to the workpiece and in the second stage the final forming was performed Fig. 13. Using a computer simulation the optimal design parameters such as flash thickness, temperature and die corner radiuses were selected. The obtained results show the great potential of FVM methods for simulation of complicated industrial process. By changing the locking gear production process from machining to forging the cost and time of production will reduce significantly.

\section{References:}

[1] C. Grobaski, B. Mehta, Preliminary Investigation into the Effects of Friction, work piece, Temperature, Die Temperature, and Stroke Speed on Hot Die Life, Department of Mechanical Engineering, Ohio University, 2004.

[2] A. Behrens, H. Schastall, 2Dand3D simulation of Complex Multistage Process bye Use Adaptive Friction Coefficient, Journal of Materials Processing Technology, Volumes 80-81, 1 August 1998, pp. 298-303.

[3] M. Wheel, A Finite Volume Method for Analyzing The Bending Deformation of Thick and Thin Plates, Computer Method In Applied Mechanics and Engineering, Volume 147, Issues 1-2, 30 July 1997, pp. 199-208.

[4] V. Ranatunga, J.S. Gunasecra, W.G Fraizer, K.D. Hur, Use of UBET for design of flash gap in closed_die, Journal of Materials Processing Technology, Volume 111, Issues 1 3, 25 April 2001, pp. 107-112.. 
Proceeding of the $14^{\text {th }}$ AMME Conference, 25 -27 May 2010 Paper MS - $17 \quad 10$

[5] Prophet Eivazi, Automatically formats designed to help round Forging computer parts, the second annual conference of Mechanical Engineering, May 1994.

[6] F.F. Saniee, M. Jaafari, Analytical, numerical \& experimental analyses of the closeddie, Volumes 125-126, 9 September 2002, pp. 334-340.

[7] Msc.Superforge, User Manual, The Mac-Sech Welder Corporation, 2004.

[8] H. Parikh, B. Mehta, Process Analysis and Perform Design, Ohio University, Current Advances in Mechanical Design and Production, Volume 3, Cairo, Egypt, Jan. 2004, pp. 117-123.

[9] M. Marumo, Effects of the Surface Structure to Plastic Deformation of a Hot Tool, Journal of Materials Processing Technology, Volume 113, 2001, pp. 22-27

[10] V. Vazquez, Die Design For Flashless of Complex Parts, Journal of Materials Processing Technology, Volume 98, Issue 1, 15 January 2000, pp. 81-89, 2000. 